\title{
The Effects of Cyclone Hudah on the Forest of Masoala Peninsula, Madagascar
}

\author{
Chris Birkinshaw \\ Miramasoandro Randrianjanahary
}

\author{
Correspondence: \\ Chris Birkinshaw \\ Missouri Botanical Garden, BP 3391 \\ Antananarivo 101, Madagascar \\ E-mail: chris.birkinshaw@mobot-mg.org
}

\begin{abstract}
Cyclones regularly impact the east coast of Madagascar but almost nothing is known about their effects on Malagasy ecosystems. On 2 April 2000 the powerful winds of Cyclone Hudah struck the humid forests in the northern part of Masoala Peninsula. An analysis of satellite images revealed that $3 \%$ of the forest here was severely damaged or $22 \%$ when just the forest of the northeast was considered. In 2001 the vegetation in this area was studied using fifteen 0.1 ha plots located in differently impacted sites. The cyclone had caused tree death (up to $53 \%$ of the trunks within a plot); a reduction in trunk basal area (to $64 \%$ ); uprooting (to $46 \%$ ); snapping of trunks (to $51 \%$ ); reduction of crown volume (to mean of $83 \%$ ); an increase in herbs, liana and woody pioneer species and decrease in saplings of primary forest species; an increase in vegetation in the "shrub" layer and decrease in vegetation in the "canopy" layer. Among a sample of 340 trees killed by the cyclone, $39 \%$ were uprooted, $37 \%$ snapped, and $24 \%$ were still standing. Mortality was relatively low for trees with either small or large trunk diameter compared to trees with intermediate size. In 2003 the plots were re-examined. Six had been impacted by human activities (fire or timber exploitation). A comparison between the vegetation in 2001 and 2003 in 6 plots that had been moderately or seriously impacted by Cyclone Hudah but not impacted by human activity revealed a further decrease in trunk density, an increase in the frequency of herbs and woody pioneers, a decrease in the frequency of liana and saplings of primary forest trees in the "shrub layer", and an increase of vegetation in the "shrub layer" but decrease of vegetation in the "canopy layer". The lack of recovery of this vegetation towards its pre-cyclone state may be explained by the impact of cyclone Ihary, in 2002. Recovery may yet occur provided the vegetation is not impacted by human activities, particularly burning, that can derail this process. It is recommended that following cyclones conservation managers prioritize fire control.
\end{abstract}

\section{INTRODUCTION}

The Masoala Peninsula in northeast Madagascar (15 30'S, $5010^{\prime} \mathrm{E}$ ) is one of the largest areas of low-elevation humid evergreen forest remaining in Madagascar. This forest is renowned for its high species diversity and high local endemism (Rabenantoandro 2001). Much of this forest is protected in the Masoala National Park, which covers 230,000 ha. The east coast of Madagascar is impacted by cyclones on average 1.4 times per year (Service de la Météorologie 2000), but Cyclone Hudah, that tore across the northern part of the Masoala Peninsula on 2 April 2000, was unusually powerful. Sustained winds of over $230 \mathrm{~km} / \mathrm{hr}$ were recorded with gusts exceeding $300 \mathrm{~km} / \mathrm{hr}$. These winds and the associated heavy rains were reported to have killed 13 people, left 50,000 homeless and 100,000 without food or drinking water. Crops, including the economically important vanilla, were devastated and infrastructure (roads, health services and schools) seriously affected. The coastal town of Antalaha was $90 \%$ destroyed (CNN 2000).

In this study we estimate the area of forest seriously damaged by this cyclone, describe the nature of this damage and describe the structure and composition of the damaged forest one year and three years after the cyclone. Although the high frequency of cyclones in Madagascar has been invoked as a possible cause for the relatively low canopy height and high trunk density of the country's humid forests compared with humid forests elsewhere in the world where cyclones are less frequent (Leigh 1988; Gouvenain and Silander 2003), their impacts on vegetation has been little described with the exception of Rasamimanana et al. (2000) who presented information showing differential damage between tree species following a violent storm at Berenty.

\section{METHODS}

The distribution of cyclone damage was studied by analyzing satellite images of the northern part of the peninsula taken in May 2000, one month after the cyclone. To distinguish between the spectral patterns produced by cyclone-damaged forest and other vegetation types (in particular land being managed by shifting cultivation) images prior to the cyclone were analyzed and ground-truthing was conducted.

The effect of the cyclone on the vegetation was investigated by describing the vegetation in a total of fifteen 0.1 ha $(50 \mathrm{~m}$ $\times 20 \mathrm{~m}$ ) plots. Twelve plots were established at four different sites in the low elevation humid forest of the lanobe River Valley and three at one site in the littoral forest adjacent to Ambohitralanana (see Figure 1) The plots were first surveyed between February to June 2001 and then again in May 2003. These sites were chosen because they are relatively easily accessible and were within the zone seriously affected by the cyclone. At each site, in order to include the range of variation in cyclone-damage 


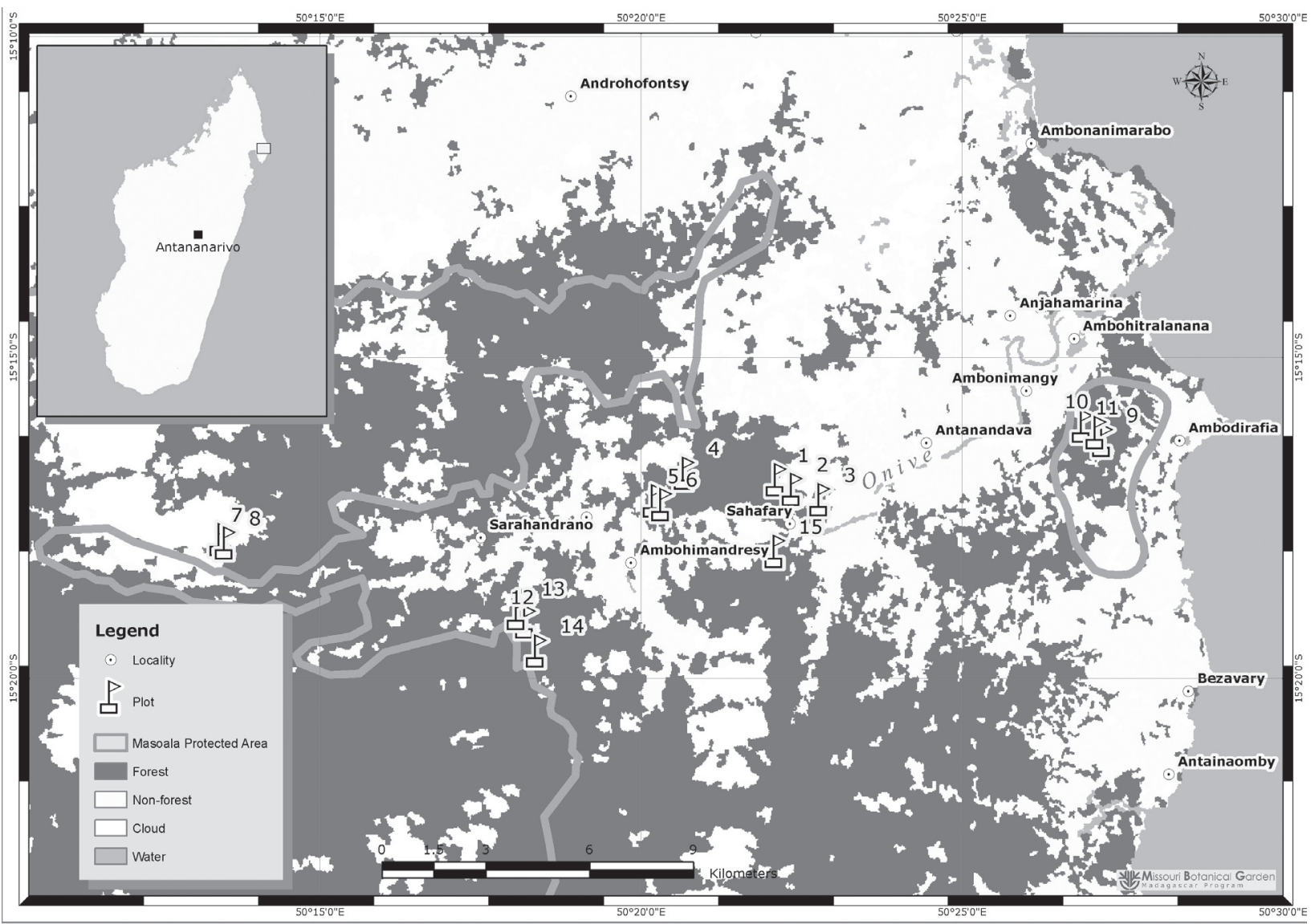

FIGURE 1. Location of plots

to the forest, we endeavored to establish one plot in forest judged subjectively to be little damaged, one in moderately damaged forest, and one in severely damaged forest.

Within each plot, all trees with diameter at breast height $(\mathrm{dbh}) \geq 10 \mathrm{~cm}$, both alive and recently killed by the cyclone, were surveyed. For each tree we noted whether it was dead or alive, measured its $\mathrm{dbh}$, and noted whether the tree was uprooted or whether the trunk had been snapped. In addition, for living trees, we estimated the proportion of crown volume that had been lost using five classes covering the range of loss in $20 \%$ intervals.

The vertical structure of the forest within the plot and the frequency of various classes of plants (i.e. primary forest tree species, woody pioneer species, liana, or herb) were also described by noting points of contact between vegetation and a survey pole held vertically at $1 \mathrm{~m}$ intervals along a 50 $\mathrm{m}$ horizontal line bisecting the plot. The data were analyzed in terms of two zones: the zone between 0 to $6 \mathrm{~m}$ from the ground (or "shrub" layer) and the zone between 6 and $24 \mathrm{~m}$ from the ground (or "canopy" layer). The upper limit of the "canopy" layer was defined by the highest vegetation encountered during the study.

\section{RESULTS AND DISCUSSION}

Satellite photos show that Cyclone Hudah damaged the forest only in the northern part of the peninsula. In total, $3.2 \%(4,627$ ha out of the 143,236 ha) of forest in this area was classified as severely damaged. However, while damage occurred right across this zone (an east-west distance of $60 \mathrm{~km}$ ), (east side of the summit of Ambatolaidama mountain) it was most extensive in the northeast where $22 \%(1,946$ ha out of 8,915 ha) of the forest was severely damaged. The most severely damaged forest was the littoral forest, and further inland, forest on east or southeast facing slopes (i.e. facing the direction of the cyclone) or adjacent to areas of cultivation. Damage generally diminished with distance from the coast.

Table 1 summarizes the effects of Cyclone Hudah on vegetation within forest subjectively classified as severely damaged, moderately damaged and undamaged by Cyclone Hudah. For each of the attributes considered there was a significant difference between the three forest types. The cyclone had caused: tree death (up to $53 \%$ of the trunks within a plot); a reduction in trunk basal area (up to $64 \%$ in a plot); uprooting (up to $46 \%$ ); snapping of trunks (up to $51 \%$ ); loss of branches leading to reduction of crown volume (up to a mean of $83 \%$ ); an increase in the frequency of herbs, liana and woody pioneer species; a small decrease in frequency of saplings of primary forest species and a small increase in the frequency of vegetation in the "shrub" layer and a large decrease in the frequency of vegetation in the "canopy" layer. Tree mortality in other tropical wet forests impacted by catastrophic winds is reported to be between $1 \%$ to $25 \%$ (Brokaw and Walker 1991; Bellingham et al. 1992; Zimmerman et al. 1994; Everham and Brokaw 1996) while reported values for snapping or uprooting range from $4.5 \%$ to $80 \%$ (Brokaw and Walker 1991; Everham and Brokaw 1996). However, it is difficult to make comparisons between studies because of differences in their experimental conditions.

Among the dead trees $(\mathrm{N}=340), 39.4 \%$ had been uprooted, $36.5 \%$ had been snapped, and $24.1 \%$ were still standing 
TABLE 1. The effects of Cyclone Hudah in three types of forest differentially impacted by the cyclone.

\begin{tabular}{|c|c|c|c|c|}
\hline & \multicolumn{3}{|c|}{ FOREST TYPE } & \multirow{2}{*}{$\begin{array}{l}\text { SIGNIFICANCE: }{ }^{*} p<0.05, * * * \\
p<0.001\end{array}$} \\
\hline & Intact (I) & Moderately damaged (M) & Severely damaged (S) & \\
\hline No. plots & 5 & 5 & 5 & \\
\hline Mean \% trunks dead & 0.2 & 19.9 & 45.6 & $\chi^{2}=394 * * *$ \\
\hline Mean \% basal area of trunks dead & 0.6 & 23.5 & 51.5 & $\begin{array}{l}\text { I versus } \mathrm{M}, \mathrm{t}=-20.9^{* * *} \\
\text { I versus } \mathrm{S}, \mathrm{t}=-31.6^{* * *} \\
\mathrm{M} \text { versus } \mathrm{S}, \mathrm{t}=-14.5^{* * *}\end{array}$ \\
\hline Mean \% trunks uprooted & 0.8 & 13.8 & 25.2 & $\chi^{2}=163^{* * *}$ \\
\hline Mean \% trunks broken & 1.1 & 16.2 & 33.7 & $\chi^{2}=222 * \star *$ \\
\hline Mean \% reduction of canopy per trunk & 16 & 60.7 & 76.4 & $\begin{array}{l}\text { I versus } \mathrm{M}, \mathrm{t}=-9.14^{* * *} \\
\text { I versus } \mathrm{S}, \mathrm{t}=-11.24^{* * *} \\
\mathrm{M} \text { versus } \mathrm{S}, \mathrm{t}=-2.4^{*}\end{array}$ \\
\hline $\begin{array}{l}\text { Mean } \% \text { frequency of herbs } \\
\text { in zone } 0-6 \mathrm{~m}\end{array}$ & 0.7 & 1.2 & 2.7 & $\chi^{2}=229 * * *$ \\
\hline $\begin{array}{l}\text { Mean \% frequency of liana } \\
\text { in zone } 0-6 \mathrm{~m}\end{array}$ & 1.5 & 1.3 & 3 & $\chi^{2}=142 * \star *$ \\
\hline $\begin{array}{l}\text { Mean } \% \text { frequency of pioneer trees } \\
\text { in zone } 0-6 \mathrm{~m}\end{array}$ & 0 & 0.1 & 0.4 & $\chi^{2}=74 * * *$ \\
\hline $\begin{array}{l}\text { Mean } \% \text { frequency of primary forest } \\
\text { trees in zone } 0-6 \mathrm{~m}\end{array}$ & 12.3 & 11.8 & 10.3 & $\chi^{2}=34 * * *$ \\
\hline $\begin{array}{l}\text { Mean total \% frequency of vegetation } \\
\text { in zone } 0-6 \mathrm{~m}\end{array}$ & 14.4 & 14.5 & 16.4 & $\chi^{2}=29 * * *$ \\
\hline $\begin{array}{l}\text { Mean total \% frequency of vegetation } \\
\text { in zone } 6-24 \mathrm{~m}\end{array}$ & 21.8 & 5.4 & 2.2 & $\chi^{2}=2293^{* * *}$ \\
\hline
\end{tabular}

(presumably dying because of the loss of branches and / or leaves). In addition, $14 \%$ of the living trees $(N=1,438)$ were either uprooted or snapped.

Table 2 shows the proportion of trees in various dbh classes that were killed, uprooted or snapped. Death and damage were lowest in the $10-20 \mathrm{~cm}$ and $>50 \mathrm{~cm}$ dbh classes and highest in the intermediate classes. This is probably because trees with small $\mathrm{dbh}$ tend to be shorter than trees with larger $\mathrm{dbh}$ and therefore less exposed to the wind, while trees with $\mathrm{dbh}>50$ $\mathrm{cm}$ are a similar height to those with $\mathrm{dbh} 20-50 \mathrm{~cm}$ but their thicker trunks are stronger. The latter hypothesis is supported by the low percentage of trunks in the $>50 \mathrm{~cm}$ dbh class that were snapped (6.1\%) compared to trunks in smaller dbh classes (13.1-17.3\%). Alternatively, the largest trees could be more abundant in relatively unexposed sites (e.g. valleys (although valleys are not always protected sites (Everham and Brokaw 1996)) or tend to be species with high resistance to damage (e.g. because of their wood density or architecture). Rasamimanana et al. (2000) report that at Berenty tree species showed differential damage to a violent wind. The relatively low mortality of the largest trees seems to contradict the hypothesis proposed by Leigh (1988) and Gouvenain and Silander (2003) that the low canopy of Malagasy rainforest is due to high cyclone frequency. However, it may be that low canopy height is less the result of large trees being differentially removed from forests by cyclones in the present but rather the consequence of the application this selective pressure in the past resulting the evolution of trees that tend not to exceed average canopy height. The relatively high proportion of trees in the $10-20 \mathrm{~cm}$ dbh class that were snapped compared to the proportion that were uprooted was probably due to their susceptibility to snapping when impacted by a falling neighbour. Walker (1991) and Zimmerman et al. (1994) also report that when impacted by a powerful wind, large trees were more likely to uproot and small trees more likely to snap, but no such relationship was found by Bellingham et al. (1992).

In 2003, the vegetation in 6 of the 15 plots previously studied had suffered human impact: 3 had been affected by the extraction of timber and 3 had been burnt when a lumberman's cooking fire burnt out of control. Of the 9 plots where the vegetation had developed naturally, 3 had been classified as intact in 2001 and 6 as either moderately or severely damaged. Table 3 compares the vegetation in this latter group in 2001 and 2003. Between these two periods there had been a significant decrease in trunk density, a significant increase in the frequency of herbs and woody pioneers, a significant decrease in the frequency of liana and saplings of primary forest trees in the "shrub layer", a significant increase in the frequency of vegetation in the "shrub layer" and a significant decrease in the frequency of vegetation in the "canopy layer". Thus it would seem that the moderately and seriously cyclone-impacted vegetation was showing no signs of return to its pre-cyclone state. This is probably due to the occurrence of a second powerful cyclone (Cyclone Ihary) in this area in 2002. It would seem that this cyclone further degraded this already damaged forest and set back its recovery. Despite the increased abundance of herbs and woody pioneer species, seedlings and saplings of woody primary forest species remain present and ultimately these should affect recovery.

Within the three plots that had been burnt, the vegetation had been very seriously impacted. In particular, nearly all plants 
TABLE 2. Percent of trees in various dbh classes that were killed, snapped, and uprooted by Cyclone Hudah.

\begin{tabular}{|l|l|l|l|l|}
\hline Trunk dbh (cm) & & & & N \\
\hline & Dead & Snapped & Up-rooted & \\
\hline$>10-20$ & 16.2 & 14.8 & 9.3 & 1,124 \\
\hline$>20-30$ & 25.5 & 13.1 & 18.7 & 396 \\
\hline$>30-40$ & 22.2 & 17.3 & 10.5 & 162 \\
\hline$>40-50$ & 25.4 & 15.9 & 12.7 & 63 \\
\hline$>50$ & 15.2 & 6.1 & 12.1 & 33 \\
\hline
\end{tabular}

of the primary forest had been killed, the layer of debris (fallen branches and trunks) had been lost and the plots had been invaded by the woody pioneer species Trema orientalis and Pteridium aquilinum. Here, recovery will require re-colonization by species from the primary forest - a process that will take a very long time and in reality, with ever increasing human pressure, is never likely to occur.

It would appear that following Cyclone Hudah the rural population, impoverished by its catastrophic winds and encouraged by a breakdown in regulatory structures, increased their exploitation of natural resources with the consequent derailing of forest recovery in many areas. Clearly a priority for conservation mangers in situations such as this should be to work with the Government and development NGO's to help local people to rebuild their lives without the abusive exploitation of natural resources. They should also understand that although cyclone-damaged forest can recover, until it does it will be highly vulnerable to burning because its fragmented canopy allows the understory, rich in cyclone debris, to dry out and also allows wind to enter the forest and fan flames. This vegetation will require intensive fire protection until the debris has rotted and the forest canopy reformed. This may require diverting limited resources away from less urgent activities: for example, following a cyclone, staff that previously worked in a tree nursery and restore a few hectares of forest each year may be better used in fire control that would reduce the risk of hundreds of hectares of cyclone-damaged forest from burning. Fire protection should be multifaceted and include awareness-raising among local stakeholders, fire patrols, creation and training of well-equipped and motivated fire-fighting teams, and the creation of fire breaks. These methods seem most effective when they fully implicate local stakeholders and, were possible, these activities should be designed to create employment in cyclone-impoverished communities. Those responsible for sites of conservation importance in cyclone-prone areas need to ready with contingency plans for the day when the inevitable happens. The donors too need to be ready with a special fund dedicated for emergency post-cyclone conservation actions that can be accessed rapidly. It is as yet unclear whether global warming is increasing frequency or power of cyclones (Young 2007), but if it is, then preparedness for cyclone-impact is even more imperative.

\section{ACKNOWLEDGEMENTS}

Thanks to Dr. Alain Randriamaherisoa for analysis of the satellite images, to Tantely Raminosoa for providing Figure 1 and to Solofo Rakotoarisoa, Patrice Antilahimena, Roger Bernard, Richard Razakamalala, Andriambolantsoa Rasolohery, and Faly Mbolatiana Randriantafika for their assistance with fieldwork. Financial support was provided by the National Geographic
TABLE 3. Comparison between the vegetation in six plots classified as the moderately or seriously impacted by Cyclone Hudah, in 2001 and 2003.

\begin{tabular}{|l|l|l|l|}
\hline & 2001 & 2003 & Significance \\
\hline No. plots & 6 & 6 & *** $p<0.001$ \\
\hline $\begin{array}{l}\text { Mean number of trees with } \\
\mathrm{dbh}>10 \mathrm{~cm} \text { ( } \pm 9 \% \text { con- } \\
\text { fidence limits) in 0.1 ha plot }\end{array}$ & $64.0 \pm 17.1$ & $40.0 \pm 8.0$ & $\mathrm{t}=12.9^{* * *}$ \\
\hline $\begin{array}{l}\text { Mean \% frequency of herbs } \\
\text { in zone 0-6 m }\end{array}$ & 2.9 & 10.6 & $\chi^{2}=865.7^{* * *}$ \\
\hline $\begin{array}{l}\text { Mean \% frequency of liana } \\
\text { in zone 0-6 m }\end{array}$ & 3.2 & 1.6 & $\chi^{2}=107.4^{* * *}$ \\
\hline $\begin{array}{l}\text { Mean \% frequency of } \\
\text { pioneer trees in zone 0-6 } \mathrm{m}\end{array}$ & 0.4 & 1.8 & $\chi^{2}=160.1^{* * *}$ \\
\hline $\begin{array}{l}\text { Mean \% frequency of } \\
\text { primary forest trees in zone } \\
\text { 0-6 m }\end{array}$ & 9.5 & 8.2 & $\chi^{2}=18.0^{* * *}$ \\
\hline $\begin{array}{l}\text { Mean total \% frequency of } \\
\text { vegetation in zone 0-6 } \mathrm{m}\end{array}$ & 16 & 22.2 & $\chi^{2}=276.8^{* * *}$ \\
\hline $\begin{array}{l}\text { Mean total \% frequency of } \\
\text { vegetation in zone 6-24 } \mathrm{m}\end{array}$ & 4 & 0.8 & $\chi^{2}=246.6^{* * *}$ \\
\hline
\end{tabular}

Society (Grant Number 6901-00). We also gratefully acknowledge courtesies extended by the Government of Madagascar (Direction Générale de la Gestion des Ressources Forestières) and by the Association Nationale pour la Gestion des Aires Protégées (ANGAP).

\section{REFERENCES}

Bellingham, P.J., Kapos, V., Varty, N., Healey, J.R., Tanner, E.V.J., Kelly, D.L., Dalling, J.W., Burns, L.S., Lee, D. and Sidrak, G. 1992. Hurricanes need not cause high mortality: the effects of Hurricane Gilbert on forests in Jamaica. Journal of Tropical Ecology 8: 217-223.

Brokaw, N.V.L. and Walker, L.R. 1991. Summary of the effects of Caribbean Hurricanes on Vegetation. Biotropica 23, 4a: 442-447.

CNN, 2000. http://edition.cnn.com/2000/WEATHER/04/04/mozambique. floods.02/index.html

Everham, E.M. and Brokaw, N.V.L. 1996. Forest damage and recovery from catastrophic wind. Botanical Review 62: 113-185.

Gouvenain de, R.C. and Silander, J.A. (2003). Do tropical storm regimes influence the structure of tropical rain forests. Biotropica 35(2): 166-180.

Rabenantoandro, J. 2001. Analyse floristique, structurale et dendrometrique de la Forêt Dense Humide de Basse Altitude du Parc National Masoala sur le versant occidental selon la méthode de la parcelle permanente. Unpubl. DEA Memoire, University of Antananarivo.

Rasamimanana, H., Ratovonirina, Jolly, A., Pride, E. 2000. Storm damage at Berenty Reserve. Lemur News 5: 7-8.

Service de la Météorologie 2000. Perturbations cycloniques à Madagascar de 1961 à 2000. Service de la Météorologie, Antananarivo.

Walker, L.R. 1991. Tree damage and recovery from Hurricane Hugo in Luquillo Experimental Forest, Puerto Rico. Biotropica 23: 379-385.

Young, E. 2007. Climate Myths: Hurricane Katrina was caused by global warming. NewScientist.com News Service. http://environment.newscientist.com/channel/earth/climate-change/dn11661.

Zimmerman, J.K., Everham III, E.M., Waide, R.B., Lodge, D.J., Taylor, C.M. and Brokaws, N.V.L. 1994. Response of tropical tree species to hurricane winds in subtropical wet forest in Puerto Rico: implications for tropical tree life histories. Journal of Ecology 82: 911-922. 